\title{
Passive Modification of a Heat Exchanger using Spherical Turbulators
}

\author{
Karan Hiranandani, Aditya Manjeshwar
}

\begin{abstract}
Heat exchangers can be enhanced by different kinds of methods, namely Active, Passive, and Compound methods. Active Methods involve supply of external power to increase the rate of heat transfer. While constructing such heat exchangers leads to a rather complex design, external power is not easy to provide in certain scenarios.

Passive Methods do not need any external power supply and improve the efficiency of the heat transfer through structural alterations. This, however, leads to utilization of energy from the available energy in the heat exchanger, thereby leading to an increased pressure drop. It has been the aim of all the scientists to obtain greater thermal contact i.e., increased heat transfer coefficient and lower pumping power.

The Passive Technique being discussed below involves the use of surface extensions. The surface extensions are further referred to as turbulators, and because of their spherical cross-section, they are conveniently termed as spherical turbulators. These Spherical Turbulators cause blockages in the flow passage. This leads to enhanced secondary flow and due to the increased surface area as well, there is an improvement in the overall heat transfer coefficient-which is manifested by an increase in the outlet temperature of the fluid to be heated and the Nusselt Number.
\end{abstract}

Index Terms-ANSYS analysis, Graphical plot and results, Heat transfer augmentation techniques, Mathematical proof,

\section{INTRODUCTION}

Heat Exchangers are devices that find application in daily industrial and domestic activities. From refineries to radiators, heat exchangers make up an important aspect of an industry's energy cost. The need for increasing the efficiency of heat exchanger can mainly be attributed to economic reasons. Higher efficiency of a heat exchanger would reduce the energy consumption. Increased efficiency for heat exchangers also leads to more compact heat exchangers. Efficient Heat Exchangers also improve the rate of heat transfer. Increasing the efficiency of heat exchangers can also reduce the volume and weight of the heat exchangers.

The design requirements for heat exchangers require multiple factors to be considered. An exact analysis of heat transfer is not the only parameter that needs to be considered-but pressure drop estimations and long term economic costs need to be accounted for as well. The biggest challenge in designing a heat exchanger involves obtaining an optimum rate of heat transfer with a minimum reduction in pressure

Karan Hiranandani, Mechanical Engineering, Manipal Institute of Technology, Mumbai, India

Aditya Manjeshwar, Mechanical Engineering, Manipal Institute of Technology, Mumbai, India across the exchanger-while trying to ensure that the heat exchanger remains compact and viable.

The increasing costs for material and energy have motivated scientists to develop methods of enhancing heat exchangers. Moreover, certain applications require smaller or compact heat exchangers with a high output. The above requirements notwithstanding, older heat exchangers tend to suffer from fouling effects. Especially, heat exchangers utilized in marine applications tend to lose their efficiency due to the corrosive effects of fluids. Therefore, in order to achieve an increased heat transfer rate at an economic pumping rate, heat transfer augmentation techniques are used.

\section{IMPORTANT TERMS}

\section{a. Thermohydraulic Performance}

For a fixed Reynolds Number, the Thermohydraulic performance is said to be optimum if the heat transfer coefficient increases significantly for a negligible increase in the friction factor. Thermohydraulic performance is a parameter that is usually used to compare different kinds of inserts and extensions the surface.

\section{b. Enhancement Ratio}

Enhancement Ratio is defined as the ratio of the product of the heat transfer coefficient and surface area of the enhanced heat exchanger to the product of the heat transfer coefficient of the surface area of the plain heat exchanger.

$$
E=\frac{h_{e} \times A_{e}}{h \times A}
$$

Where: $h_{e}=$ Heat Transfer Coefficient for an enhanced Heat Exchanger Exchanger

$\mathrm{h}=$ Heat Transfer Coefficient for a plain Heat

$A_{e}=$ Surface Area of an enhanced Heat Exchanger

$A=$ Surface Area of a plain Heat Exchanger

\section{c. Overall Enhancement Ratio}

Overall Enhancement Ratio is defined as the ratio of the Enhancement Ratio to the friction factor ratio. This parameter is compared for different constant pressure drops. This is a useful parameter to compare different passive techniques.

$$
E_{o}=\frac{\left(N u_{e} / N u\right)}{\left(f_{\mathrm{f}} / f\right)^{1 / 3}}
$$


Where $\mathrm{Nu}_{\mathrm{e}}=$ Nusselt number of enhanced Heat Exchanger $\mathrm{Nu}=$ Nusselt Number of plain Heat Exchanger $\mathrm{f}_{\mathrm{e}}=$ Frictional factor of enhanced Heat Exchanger $\mathrm{f}=$ Frictional factor of plain Heat Exchanger

\section{d. Pitch}

Pitch is defined as the distance between two adjacent turbulators, measured along the horizontal axis of the Heat Exchanger.

\section{Heat Augmentation techniques}

Turbulators are placed in the flow passage to augment the heat transfer rate, and this reduces the hydraulic diameter of the flow passage. Heat Transfer by inserts such as twisted tape coils, spherical turbulators leads to flow blockage - portioning the flow into primary flow and secondary flow. While this may lead to an increased pressure drop, it increases the net viscous effects. This also increases the flow velocity and may augment the secondary boundary flow as well. Secondary flow further provides a better thermal contact between the surface and the fluid because secondary flow creates swirl and the resulting mixing of fluid improves the temperature gradient, which ultimately leads to a high heat transfer coefficient.

There are three techniques for heat transfer augmentation
a. Active Method
b. Passive Method
c. Compound Method

Active Method involves supply of external power to increase the rate of heat transfer. While constructing such heat exchangers leads to a rather complex design, external power is not easy to provide in certain scenarios. Some examples of active methods are induced pulsation by cams and reciprocating plungers, the use of a magnetic field to disturb the seeded light particles in a flowing stream, etc.

Passive Methods do not need any external power supply and improve the efficiency of the heat transfer through structural alterations. This, however, leads to utilization of energy from the available energy in the heat exchanger, thereby leading to an increased pressure drop. It has been the aim of all the scientists to obtain greater thermal contact i.e., increased heat transfer coefficient and lower pumping power. Common Passive Methods include incorporating inserts, creating rough surfaces, employing turbulators, baffles, or any form of surface additives.

Compound Methods involve two or more methods being employed simultaneously.

\section{ILLUSTRATION OF HEAT TRANSFER ENHANCEMENT BENEFITS MATHEMATICALLY}

$$
Q=U A \Delta T_{m}
$$

Where $\mathrm{U}$ is the overall heat transfer coefficient $A$ is the surface area from which the heat is exchanged

$\Delta T_{m}$ is the mean temperature difference
Multiplying and Dividing by the length of the heat exchanger $\mathrm{L}$

$$
Q=\frac{U A}{L} L \Delta T_{m}
$$

Where $\frac{L}{U A}$ is the thermal resistance per unit tube length, Such that

$$
\frac{L}{U A}=\frac{L}{n_{1} h_{1} A_{1}}+\frac{L t_{w}}{k_{w} A_{m}}+\frac{L}{n_{2} h_{2} A_{2}}
$$

Where the subscripts 1 and 2 refer to the different fluids in the heat exchanger

$t_{w}=$ Temperature of the wall $\mathrm{k}_{\mathrm{w}}=$ Specific heat conductivity of the wall $A_{m}=$ Mean surface area for both the fluids $n=$ refers to the surface efficiency due to employment of surface extensions

Please note that the effect of fouling resistance has been neglected

It is evident that to increase the rate of heat transfer, the value of $\frac{U A}{L}$ needs to be increased i.e. the value of $\frac{L}{U A}$ needs to be reduced. This is possible by increasing the value of ${ }^{n}$, which can be obtained by enhancing the surface geometry.

The reduction in the value of $\frac{L}{U A}$ has three major applications

1. Size reduction/Increasing compactness of heat exchanger: The reduction in $\frac{L}{U A}$ can be effected by reducing the length of the heat exchanger, which is likely to make it more compact.

2. Increased rate of heat transfer or reduction in $\Delta T_{m \text { : }}$ : The reduction in $\frac{L}{U A}$ can also be demonstrated by increasing the value of UA, which will lead to greater heat exchange. If $\mathrm{Q}$ is kept constant, an increase in UA might lead to reduction $\Delta T_{m}$.

3. Reduced Pumping Power for fixed duty: Although it may seem surprising that enhanced surfaces can provide reduced pumping power, this is theoretically possible. However, this will typically require that the enhanced heat exchanger operates at a velocity smaller than the competing plain surface. This will require increased frontal area, which is normally not desired.

The principle demonstrated here is that heat augmentation techniques can lead to either one of the three objectives mentioned above. The application selected depends on the requirement. Thus, a surface enhancement that provides the given amount of heat transfer enhancement with a minimal pressure drop is usually preferred. 


\section{HEAT ENHANCEMENT USING SPHERICAL TURBULATORS}

The Passive Technique being discussed below involves the use of surface extensions. The surface extensions are further referred to as turbulators, and because of their spherical cross-section, they are conveniently termed as spherical turbulators.

These Spherical Turbulators cause blockages in the flow passage. This leads to enhanced secondary flow and due to the increased surface area as well, there is an improvement in the overall heat transfer coefficient - which is manifested by an increase in the outlet temperature of the fluid to be heated and the Nusselt Number. However, presence of these turbulators also leads to an increase in the pressure drop. The challenge is to obtain the optimum point where the heat transfer is optimum and the pressure drop is negligible-in other words, a good thermohydraulic performance. Parameters like the mass flow rate of the cool fluid is varied.

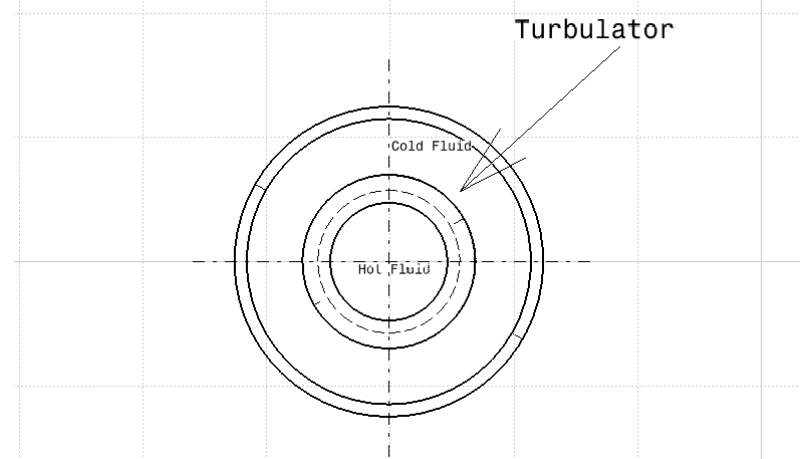

Fig. 1: Side view of the enhanced heat exchanger

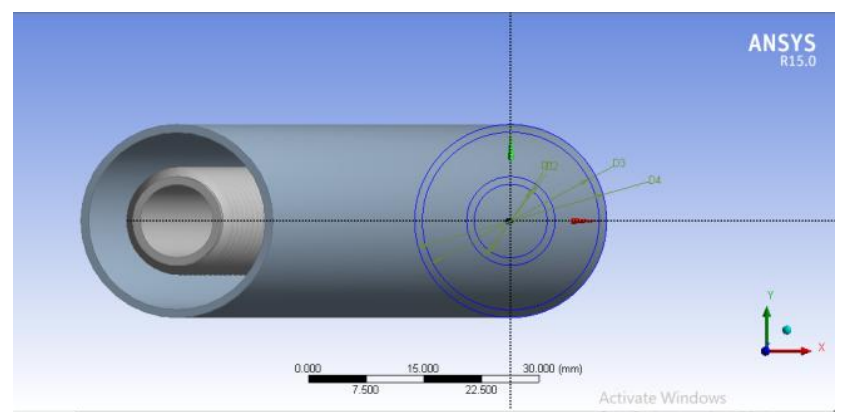

Fig. 2: Isometric view of the enhanced heat exchanger

\section{THERMAL ANALYSIS OF A HEAT EXCHANGER WITH SPHERICAL TURBULATORS}

A heat exchanger, as shown above, is utilized to heat a cold stream of air. Analyse the effects of the variation of mass flow rate of the cold fluid in case of a Parallel Flow. Compare the results obtained in case of an Enhanced Heat Exchanger and a Plain one.

Note: The following calculations are carried out under turbulent conditions for the cold fluid

\section{A. Given Data}

1. Hot fluid (flowing through inner pipe): Water

2. Cold Fluid (flowing through outer pipe): Air

3. Inlet Water Temperature $\mathrm{T}_{\mathrm{hi}}=333 \mathrm{~K}$

4. Inlet Air Temperature $\mathrm{T}_{\mathrm{ci}}=293 \mathrm{~K}$

5. Density of air at $293 \mathrm{~K} P=1.225 \mathrm{~kg} / \mathrm{m} 3$

6. Prandtl Number $\operatorname{Pr}=0.71$
7. Dynamic viscosity of air at $293 \mathrm{~K}{ }^{\mu}=1.82^{\mathrm{X}_{10-5}}$ $\mathrm{kg} / \mathrm{m} . \mathrm{s}$

8. Specific Heat Capacity of Air $\mathrm{Cp}=1.006^{\mathrm{X}_{10}} \mathrm{~J} / \mathrm{kg} . \mathrm{K}$

9. Thermal conductivity $\mathrm{k}=0.026 \mathrm{~W} / \mathrm{m} . \mathrm{K}$

10. Material of Construction for Inner and Outer pipe: Copper

11. Diameter of inner pipe $d_{i}=11.5 \mathrm{~mm}$

12. Diameter of outer pipe $d_{0}=23 \mathrm{~mm}$

13. Mass flow rate of hot fluid $m_{h}=0.05 \mathrm{~kg} / \mathrm{s}$

14. Reynolds number of cold fluid $=3000$

15. Length of heat exchanger $\mathrm{L}=1000 \mathrm{~mm}$

B. For Plain Heat Exchangers

$$
\begin{gathered}
N u=0.023 \times(R e)^{0.8} \times(P r)^{0.33} \\
=0.023 \times(3000)^{0.8} \times(0.71)^{0.33} \\
N u=12.43 \\
N u=\frac{(h \times D)}{k}
\end{gathered}
$$

Where $\mathrm{D}=$ Hydraulic Diameter $=$ do-di

$$
\begin{gathered}
\mathrm{D}=23-11.5=11.5 \mathrm{~mm} \\
h=\frac{12.43 \times 0.026}{11.5 \times 10^{-3}} \\
\boldsymbol{h}=\mathbf{2 8 . 0 9} \mathrm{W} / \mathrm{m}^{2} \mathrm{~K}
\end{gathered}
$$

The following model was simulated in ANSYS and the outlet temperature for the cold fluid was found to be $\mathbf{T}_{\mathbf{c o}}=\mathbf{3 1 7 . 3 4 K}$

$$
\begin{gathered}
\text { Rate of Heat Transfer } Q=h \times A \times\left(T_{c i}-T_{c o}\right) \\
Q=28.09 \times \pi \times 0.0115 \times 1 \times(317.34-293) \\
Q=\mathbf{2 4 . 7 0 1 W}
\end{gathered}
$$

\section{For Enhanced Heat Exchangers}

The same experiment was carried out for an enhanced heat exchanger with spherical turbulators

1. Diameter of the spherical turbulators $=14 \mathrm{~mm}$

2. Pitch of the turbulators $=15 \mathrm{~mm}$

3. Number of turbulators $=65$

A simulation was run on ANSYS keeping all parameters constant and the following results were obtained

$$
\begin{gathered}
N u_{e}=15.3 \\
h_{e}=46.41 \mathrm{~W} / \mathrm{m}^{2} \mathrm{~K} \\
Q_{e}=40.28 \mathrm{~W}
\end{gathered}
$$

Thus, we can see that due to enhancement, the second application has been realised, i.e., increase in the rate of heat transfer in case of an enhanced heat exchanger.

The same procedure was repeated for the plain heat exchanger and the enhanced heat exchanger by varying the mass flow rates of the cold fluid, and keeping the pitch 
constant. A list of results was obtained and tabulated. The tabulated results are available in the Appendix.

\section{GRAPHICAL AND CONTOUR PLOTS}

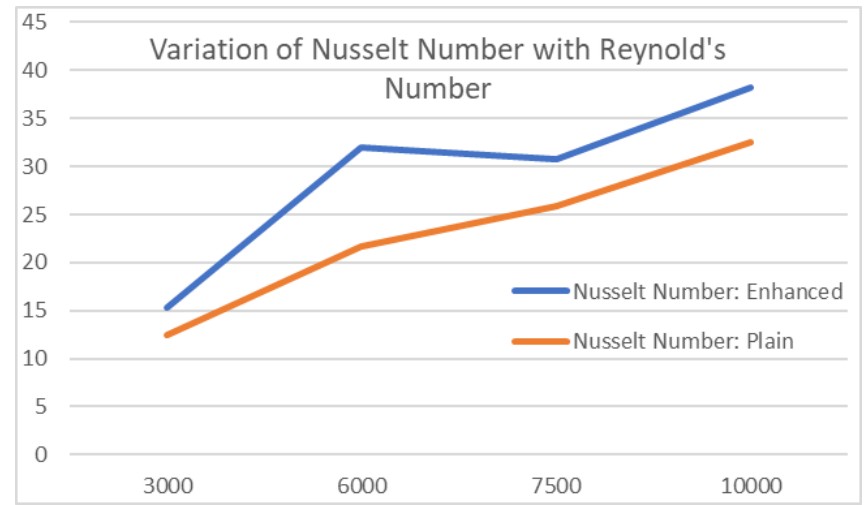

Fig. 3: Variation of Nusselt Number with Reynold's Number

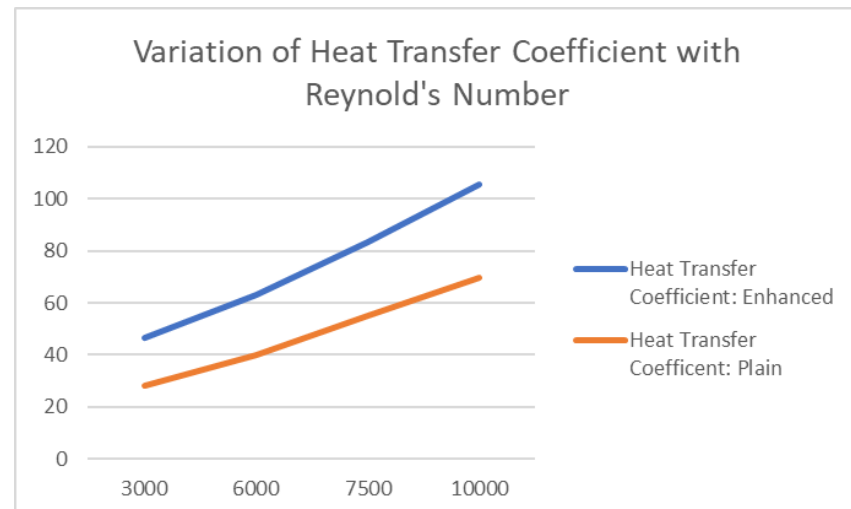

Fig. 4: Variation of Heat Transfer Coefficient with Nusselt Number

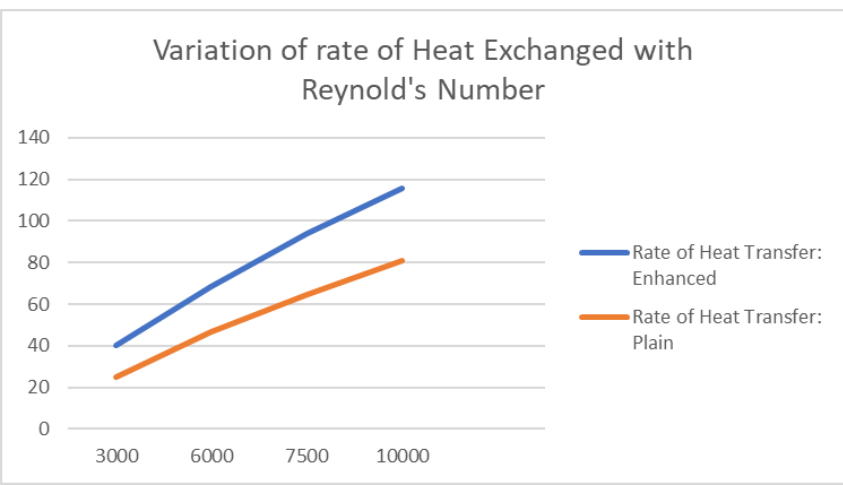

Fig. 5: Variation of Heat Exchanged with Reynold's Number

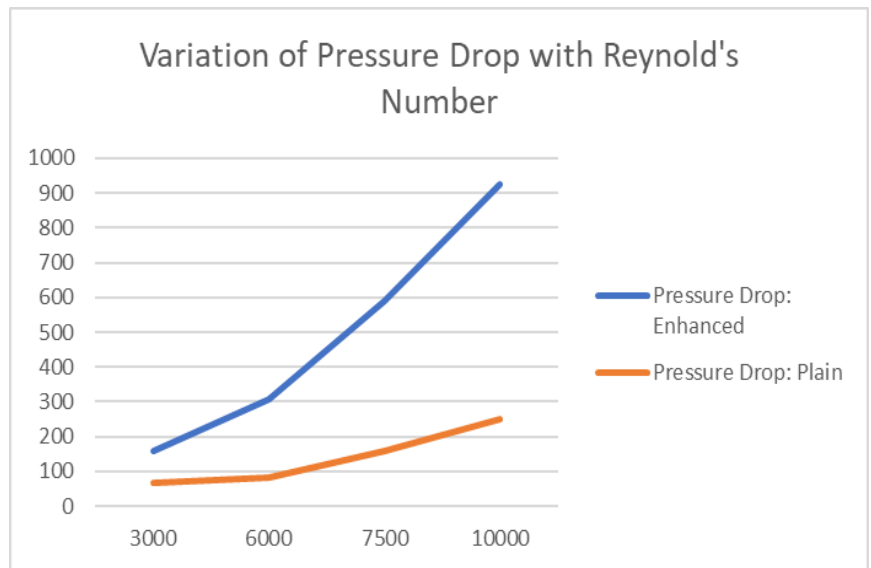

Fig. 6: Variation of Pressure Drop with Reynold's Number

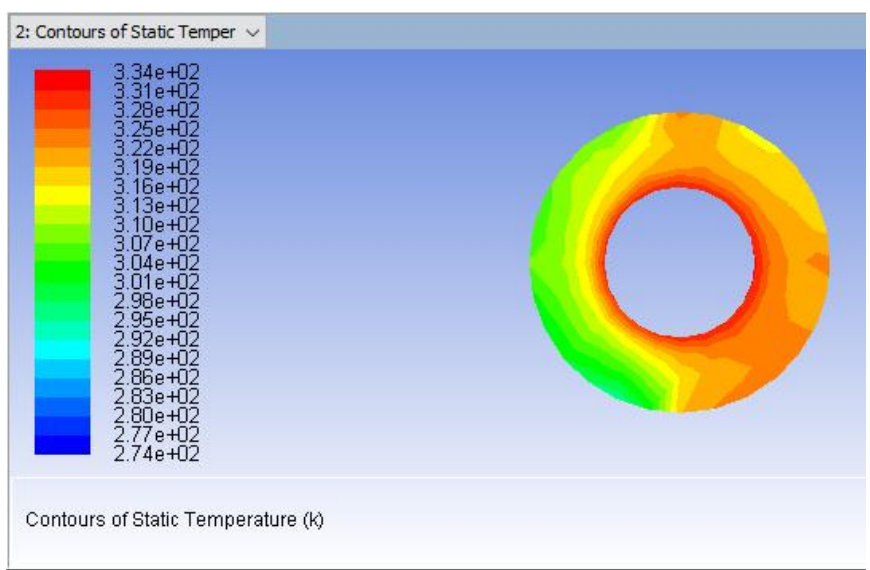

Fig. 7: Contours of Static Temperature (Without Turbulator)

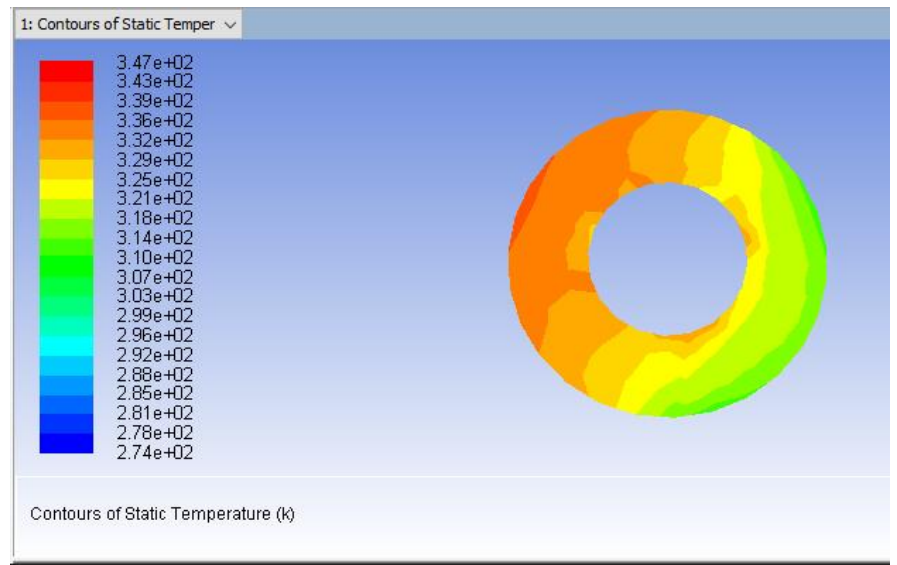

Fig. 8: Contours of Static Temperature (With Turbulator)

\section{CONCLUSION}

From the above calculations, we can see a significant increase in the rate of heat transfer and outlet temperature of the cold fluid with the application of spherical turbulators. There are different kinds of surface extensions available too-twisted tape, fins etc. However, application of these modifications may result in greater heat transfer, but it also leads to an 
increased pressure drop-which requires greater pumping power. Thus, the choice of modifications in a heat exchanger depends, to a large extent, on the requirements of the customer. If a certain customer requires supply of fluid at minimal pressures through a compact heat exchanger, or can supply high pumping power, application of surface modifications like the spherical turbulator is highly recommended. However, applications where pressure of the outgoing fluid is an important parameter and there is a lack of high pumping power, such modifications are not recommended.

\section{APPENDIX}

\begin{tabular}{|c|c|c|c|c|c|c|c|c|c|}
\hline \multicolumn{10}{|c|}{ Table 1 Results obtained from ANSYS for a Plain Heat Exchanger } \\
\hline \multicolumn{10}{|c|}{ Pitch=15mm; Turbulator Diameter $=14 \mathrm{~mm}$} \\
\hline Density & $\begin{array}{l}\text { Hydraulic } \\
\text { Diameter }\end{array}$ & $\begin{array}{l}\text { Dynamic } \\
\text { Viscosity }\end{array}$ & $\begin{array}{c}\text { Reynold's } \\
\text { Number }\end{array}$ & Velocity & $\begin{array}{l}\text { Outlet } \\
\text { Tempe } \\
\text { rature }\end{array}$ & $\begin{array}{c}\text { Heat } \\
\text { Excha } \\
\text { nged }\end{array}$ & $\begin{array}{l}\text { Pressur } \\
\text { e Drop }\end{array}$ & $\begin{array}{c}\text { Heat } \\
\text { Transfer } \\
\text { Coefficient }\end{array}$ & Nusselt Number \\
\hline $\mathrm{kg} / \mathrm{m}^{\wedge} 3$ & M & $\mathrm{kg} / \mathrm{m} . \mathrm{s}$ & & $\mathrm{m} / \mathrm{s}$ & $\mathrm{K}$ & $\mathrm{W}$ & $\mathrm{Pa}$ & $\mathrm{W} / \mathrm{m}^{2} \mathrm{~K}$ & \\
\hline 1.225 & 0.0115 & $1.82 \mathrm{E}-05$ & 3000 & 3.8757 & 317.3 & 24.7 & 65.9 & 28.09 & 12.43 \\
\hline 1.225 & 0.0115 & $1.82 \mathrm{E}-05$ & 6000 & 7.7515 & 314.8 & 46.66 & 84.3 & 39.78 & 21.64 \\
\hline 1.225 & 0.0115 & $1.82 \mathrm{E}-05$ & 7500 & 9.6894 & 313.1 & 64.4 & 158.6 & 55.12 & 25.86 \\
\hline 1.225 & 0.0115 & $1.82 \mathrm{E}-05$ & 10000 & 12.919 & 312.0 & 80.81 & 249.01 & 69.5 & 32.56 \\
\hline
\end{tabular}

\begin{tabular}{|c|c|c|c|c|c|c|c|c|c|}
\hline \multicolumn{10}{|c|}{ Table 2 Results obtained from ANSYS for an Enhanced Heat Exchanger with Spherical Turbulators } \\
\hline \multicolumn{10}{|c|}{ Pitch $=15 \mathrm{~mm} ;$ Turbulator Diameter $=14 \mathrm{~mm}$} \\
\hline Density & $\begin{array}{l}\text { Hydraulic } \\
\text { Diameter }\end{array}$ & $\begin{array}{l}\text { Dynamic } \\
\text { Viscosity }\end{array}$ & $\begin{array}{l}\text { Reynold's } \\
\text { Number }\end{array}$ & Velocity & $\begin{array}{l}\text { Outlet } \\
\text { Tempe } \\
\text { rature }\end{array}$ & $\begin{array}{l}\text { Heat } \\
\text { Exhch } \\
\text { anged }\end{array}$ & $\begin{array}{l}\text { Pressure } \\
\text { Drop }\end{array}$ & $\begin{array}{l}\text { Heat Transfer } \\
\text { Coefficient }\end{array}$ & $\begin{array}{l}\text { Nusselt } \\
\text { Number }\end{array}$ \\
\hline $\mathrm{kg} / \mathrm{m}^{\wedge} 3$ & $\mathrm{~m}$ & $\mathrm{~kg} / \mathrm{m} . \mathrm{s}$ & & $\mathrm{m} / \mathrm{s}$ & $\mathrm{K}$ & $\mathrm{W}$ & $\mathrm{Pa}$ & $\mathrm{W} / \mathrm{m}^{2} \mathrm{~K}$ & \\
\hline 1.225 & 0.0115 & $1.82 \mathrm{E}-05$ & 3000 & 3.87577 & 326.5 & 40.3 & 157.19 & 46.4 & 15.3 \\
\hline 1.225 & 0.0115 & $1.82 \mathrm{E}-05$ & 6000 & 7.75155 & 324.37 & 68.39 & 305.5 & 63.27 & 32.03 \\
\hline 1.225 & 0.0115 & $1.82 \mathrm{E}-05$ & 7500 & 9.68944 & 321.7 & 93.8 & 589.27 & 83.2 & 30.76 \\
\hline 1.225 & 0.0115 & $1.82 \mathrm{E}-05$ & 10000 & 12.9192 & 319.61 & 115.52 & 925.13 & 105.75 & 38.25 \\
\hline
\end{tabular}

\section{ACKNOWLEDGMENTS}

We would like to express our sincere gratitude to Dr Shiva Kumar for his guidance throughout the entirety of this paper. Without his technical expertise and experience, the compilation of this paper would not be possible.

\section{REFERENCES}

[1] A Dewan, P Mahanta, K Sumithra Raju, and P Suresh Kumar: Review of Passive Heat Transfer Augmentation Techniques.

[2] Dr A K Satapathy: CFD Analysis of Heat Transfer using ANSYS Fluent

[3] Prof K D Devade, Mr Shekhar Babar: Review on Heat Transfer Enhancement with Twisted Tape.

[4] Prof Min Zeng, Xi'an Jiaotong University: Lecture on Techniques of Heat Transfer Enhancement and their Applications 